\title{
Effects of County Public Hospital Reform on Procurement Costs and Volume of Antibiotics: A Quasi-Natural Experiment in Hubei Province, China
}

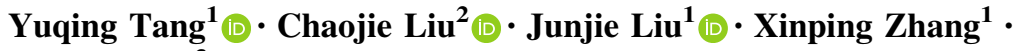 \\ Keyuan Zuo ${ }^{3}$
}

Published online: 18 April 2018

(C) The Author(s) 2018

\begin{abstract}
Background The overuse of antibiotics has become a major public health challenge worldwide, especially in low- and middle-income countries, including China. In 2009, the Chinese government launched a series of measures to de-incentivise over-prescription in public health facilities, including decoupling the link between facility income and the sale of medicines.

Objectives We evaluated the effects of these measures on procurement costs and the volume of antibiotics in county public hospitals.

Methods The study was undertaken in the Hubei province of China, where 64 county public hospitals implemented the reform in sequence at three different stages. A quasinatural experiment design was employed. We performed generalised linear regressions with a difference-in-differences approach using 22,713 procurement records of antibiotics from November 2014 to December 2016.
\end{abstract}

Electronic supplementary material The online version of this article (https://doi.org/10.1007/s40273-018-0654-1) contains supplementary material, which is available to authorized users.

Xinping Zhang

xpzhang602@hust.edu.cn

Keyuan Zuo

418754084@qq.com

1 School of Medicine and Health Management, Tongji Medical College, Huazhong University of Science and Technology, Wuhan 430030, People's Republic of China

2 School of Psychology and Public Health, La Trobe University, Kingsbury Drive, Melbourne, VIC 3086, Australia

3 Hubei Public Resource Trading Center, No. 252 Zhongbei Road, Wuhan 430030, People's Republic of China
Results The regression results showed that the reform contributed to a $14.79 \%$ increase in total costs for antibiotics $(p=0.013)$, particularly costs for injectable antibiotics $(p=0.022)$ and first-line antibiotics $(p=0.030)$. The procurement prices for antibiotics remained largely comparable to those in the control group, but the reform led to a $17.30 \%$ increase in the procurement volume (expressed as defined daily doses) of second-line antibiotics $(p=0.032)$. Conclusions County public hospitals procured more antibiotics and greater numbers of expensive antibiotics, such as those administered via injection, to compensate for the loss of income from the sale of medicines, leading to an increased total cost of antibiotics.

\section{Key Points}

Public hospital reform in China's Hubei province includes a zero markup (from wholesale to retail) policy for medicines (to reduce the cost of medicines) and increased fee levels for consultations and services (to compensate for the loss of revenue from the sale of medicines).

This reform has had some unintended consequences, with county public hospitals procuring more antibiotics and greater numbers of expensive antibiotics, such as those administered via injection, leading to an increased total cost of antibiotics.

Piecemeal remedies in hospital reform rarely fix a problem without unintended consequences if health organisations can easily find a way to take advantage of the reform for their own financial gain. 


\section{Introduction}

The irrational over-use of antibiotics has been identified as a key driver for the rapid development and spread of antibiotic resistance, an alarming global public health threat [1]. Concern about a potential shortage of effective antibiotics is increasing [2]. It is estimated that about 700,000 deaths worldwide are attributable to drug-resistant infections every year. This figure could surpass 10 million by 2050 if the rising trend of antibiotic resistance does not slow, resulting in an estimated \$US100 trillion loss in global economic output [3-5].

The overuse of antibiotics is a serious problem in China [6]. A growing body of literature reveals very high numbers of antibiotic prescriptions in both outpatient and inpatient settings in China: $41-60 \%$ of patient encounters involve an antibiotic prescription; antibiotic injections are used in 21-60\% of patient encounters [7-9]. A recent study showed that the use of antibiotics per capita (including cephalosporins, quinolones, macrolides, and all antibiotics combined) in Shanghai is higher than that in most European countries [10]. Indications are clear that irrational antibiotic prescriptions are common across all health facilities in China. For example, antibiotics are commonly prescribed for upper respiratory tract infections: $77 \%$ in tertiary hospitals, $85 \%$ in secondary hospitals, and $91 \%$ in primary hospitals [11]. The direct cost associated with the overuse of antibiotics in China is estimated to be around 2.91-13.93 billion yuan (\$US0.42-2.02 billion) per year [12].

It is widely believed that the over-prescription of medicines in China has its roots in the distorted pricing system introduced when China transitioned from a planned economy to a market economy in the 1980s. The government previously contributed to $>50 \%$ of the total revenues of public hospitals, but this fell to merely $10 \%$ within a few years $[13,14]$. The government developed two strategies to maintain the affordability of medical care and the operational viability of public hospitals. First, government-subsidised social health insurance programs were developed to reduce the financial burden on consumers. Second, a feefor-service schedule was imposed on hospital services, keeping consultation fees low while allowing hospitals to charge more for high-tech diagnostic services and maintain a $15 \%$ profit margin on the sale of medicines. As a result, public hospitals were incentivised to increase revenues through enhancing service capacities and shifting priorities from consultation services to high-tech diagnostic services and prescriptions. In hospitals, bonus payments linked closely to hospital revenues became the most important instrument for employee motivation, with bonus payments accounting for an average of about half the total salary of hospital employees [15]. Such financial arrangements, combined with the increasingly autonomous clinical decision making of medical workers, translated into a strong incentive for medical workers to overprescribe medicines, particularly more expensive ones [16]. Pharmaceutical suppliers also took advantage of the distorted pricing schedule, inflating prices, promoting more expensive products, and encouraging over-prescription through volume-based commissions. The professional integrity of medical practice was seriously jeopardised, with physicians even receiving under-the-table kickbacks from pharmaceutical salespeople [17, 18]. Antibiotics became one of the most commonly abused pharmaceutical products $[19,20]$.

To curb the inflated prices and the overuse of medicines, the Chinese government instituted several policy interventions, including enforcing a price ceiling on some targeted products such as antibiotics [21, 22], issuing antibiotic guidelines, and imposing a target on the sale of medicines as a percentage of the total revenue of hospitals $[2,23,24]$. Unfortunately, the outcome was unexpected. Prescribers responded by switching prescriptions to products that were exempted from a price ceiling and/or increasing the volume of lower priced products $[25,26]$. By 2007, sales of medicines still accounted for more than $41 \%$ of hospital revenues, and the overuse of antibiotics remained prevalent [27].

In 2009, the Chinese government launched a comprehensive package of health system reforms. Key measures included boosting government spending on health, establishing universal health insurance coverage, implementing a national essential medicines list policy for primary care, and ensuring equal access to basic public health services for all. A regional government tendering platform was set up for the procurement of medicines. Meanwhile, a zeromarkup policy on the sale of medicines was introduced in primary care facilities [28, 29]. Empirical evidence indicates that revenues from the sale of medicines in primary care facilities dropped, as intended [30-32].

The zero-markup policy on the sale of medicines was later gradually extended to public hospitals, with the intention of completely eradicating the perverse incentives for the overuse of medicines. However, unlike their primary care counterparts, public hospitals did not obtain full budgetary support from the government. They had to depend on adjusted (increased) fee levels on other items, such as consultations, physical examinations, injections and other services requiring high-level professional skills to compensate for the loss of revenue from the sale of medicines [33]. This increased the chance of cost shifts. There are concerns that cost shifts may involve changing prescription patterns, which can be detrimental to overall policy goals (e.g. containing total expenditure on medicines). 
In this study, we evaluated the impact of the reform on procurement volume and cost of antibiotics in county public hospitals. County public hospitals account for 50\% of patient admissions in China and $40 \%$ of the total expenses of all medical institutions [34, 35]. Evidence on the effects of county public hospital reform has been mixed. A study in Zhejiang revealed a reduction in total expenses and expenses for prescribed medicines for both outpatient and inpatient care despite increased service-related charges [36], but a study in Hubei showed a prolonged length of stay and increased spending for inpatient care [37]. Studies on the effects of the reform on prescribing patterns (as indicated in procurement volume and costs) are limited.

\section{Methods}

\subsection{Settings}

This study was conducted in Hubei province, central China, which has a population of over 58 million (in 2014) across a geographic area of $185,900 \mathrm{~km}^{2}$. The annual average income per capita in Hubei ranks in the middle range of all provinces: 10,849.1 yuan (\$US1647) versus a country average of 10,488.9 (\$US1593) for rural residents, and $24,852.3$ yuan (\$US3773) versus a country average of 28,843.9 (\$US4380) for urban residents (year 2014 values) [38]. The total health expenditure in Hubei accounted for $4.45 \%$ of its gross domestic product (GDP). Approximately 2.17 registered physicians, 2.48 nurses, and 5.46 hospital beds per 1000 people were available in Hubei in 2014 [39].

\subsection{Design}

We employed a quasi-natural experiment design with a difference-in-differences (DID) approach in this study. Our primary concern was the impact of the public hospital reform on procurement volume and costs of antibiotics in county hospitals.

Hubei has 64 counties, each with one general public hospital and several other hospitals specialising in traditional medicine, maternal healthcare, child healthcare and others. Our study was restricted to the 64 general public hospitals because they were mandated to implement the hospital reform measures, whereas the other hospitals voluntarily participated in the reform.

The 64 county hospitals commenced the reform in sequence over four stages: 20 started in June 2012, three started in October 2013, 15 joined in November 2014; and the remaining 26 hospitals implemented the reform in November 2015.
Key measures in the hospital reform included removing the markup on the sale of medicines in county public hospitals and increasing fees for consultations and skilled services. County public hospitals follow the fee schedules established by the provincial government. In the reformed fee schedule, $50 \%$ of items relating to medical examinations, $80 \%$ related to nursing, and $<25 \%$ relating to diagnostic and surgical procedures were subject to a $15-80 \%$ fee increase [40]. It is important to note that the reform was implemented and expanded incrementally. While the participating county hospitals selected by the government had to implement the new fee schedule, the non-participating hospitals continued to use the old fee schedule. Although the government also issued an ambitious plan to reform payment mechanisms and human resource management in public hospitals, no detailed guidelines were provided. Little, if any, action was put into practice [37].

We used the procurement records from the Hubei Medical Procurement Administrative Procurement System (HMPAPS) for this study. We only had access to procurement data from November 2014 onwards. At the time, 38 hospitals had already implemented the reform. As data on these hospitals before the reform were lacking, we changed our test hypothesis to "whether not implementing the reform would influence the procurement of antibiotics". In so doing, the pre-post reform changes made by the 26 hospitals (test group) that implemented the reform in December 2015 were compared with those of the 38 county hospitals (control group) that implemented the reform throughout the entire study period (November 2014 to December 2016). The DID results reflect the differences between the two groups of hospitals between November 2014 and November 2015.

\subsection{Data Source}

The HMPAPS is the only government-run online platform through which public-owned health facilities in Hubei may procure pharmaceutical products. It was introduced in 2009, starting with a function supporting primary care institutions. In September 2014, its function was expanded to support hospitals, and it became the only avenue of pharmaceutical procurement for all public-owned health facilities in Hubei. The HMPAPS records the type and volume of medicines purchased by a facility but does not capture information about medicines in stock, prescribed and dispensed, or expired and discarded.

Records on procured medicines categorised as anatomical therapeutic chemical (ATC) classification code "J01" (antibiotics) were extracted from HMPAPS for analyses. They were further classified into subgroups according to the administration route (oral vs. injection) and 
recommended usage (first, second and third line). This resulted in 22,713 procurement records for the 64 county hospitals over the 25-month period from November 2014 to December 2016.

\subsection{Statistical Analysis}

Three outcome indicators (volume, cost and price) were calculated to examine the impact of the reform on the procurement of all antibiotics and the subgroups. These indicators have been commonly used in previous studies [41]. The volume of procured medicines was estimated using defined daily dose (DDD), a measurement developed by the World Health Organization (WHO). The cost of procured medicines was expressed in absolute monetary terms (Chinese Yuan, CNY) without adjustment for inflation. The price of the procured medicines was calculated as unit price per DDD.

We performed DID analyses using generalised linear regressions since the outcome indicators did not follow a normal distribution.

$Y_{i j t}=\alpha_{0}+\beta \times \operatorname{Reform}_{i j t}+\gamma \times X_{j t}+\alpha_{j}+\delta_{t}+\varepsilon_{i j t}$,

where $i$ indicates the specific antibiotic product, $j$ indicates the county hospital, and $t$ indicates the month. $\alpha_{i}$ is a series of fixed effects of individual hospitals that control for the unobserved time-invariant individual heterogeneity across hospitals. $\delta_{t}$ represents month dummies used for controlling for the flexible month effects. $\varepsilon_{i j t}$ refers to the error term. The key variable of interest is Reform $_{i j t}$, which is a dummy variable, with 1 indicating the 26 hospitals before implementation of the reform (November 2015) and 0 otherwise. The coefficient $\beta$ captures the average effects of the reform on the outcome indicators. $X_{j t}$ is a set of timevarying county covariates, including year-end population, GDP per capita, fiscal revenue as a percentage of GDP, share of new technology output as a percentage of GDP, per capita disposable income of urban residents, and urban-rural ratio of per capita disposable income. Standard errors are clustered at the level of antibiotic products.

The hospitals that implemented the policy first tended to be in counties with a higher GDP per capita, a higher share of new technology outputs as a percentage of GDP, and a higher per capita disposable income for urban residents than the other counties (Table 1).

We used modified Park tests to estimate family distribution and Box-Cox tests to estimate link function [37]. More specifically, we used log link and Gamma distribution for volume (DDDs) and cost; log link and Poisson distribution for the unit price of all antibiotics, injectable antibiotics, and first- and second-line antibiotics; log link and Gamma distribution for the unit price of oral antibiotics; and identity link and Gaussian distribution for the unit price of third-line antibiotics (Table 2). We used the Benjamini-Hochberg procedure [42] to adjust the $p$ values in the multiple comparisons by setting up the false discovery rate at 0.15 .

\section{Results}

On average, 907,380 CNY were spent on procuring antibiotics per hospital per month over the study period: 489,848 CNY in the test group for 13,668 DDDs compared with $961,958 \mathrm{CNY}$ in the control group for 23,339 DDDs (average monthly value $\times$ number of hospitals $\times$ number of months). Regardless of the groups, the cost for injectable antibiotics accounted for about $90 \%$ of the overall cost (range 88.86-92.07). The majority of procured antibiotics were first-line (67\% of DDDs) and second-line (31\% of DDDs) antibiotics. In both groups, the volume and costs of the procured antibiotics increased after December 2015 when all the hospitals had implemented the reform (Table 3).

The average unit price per DDD of procured antibiotics varied considerably: oral (15-21 CNY) and first-line (29-38 CNY) antibiotics were much cheaper than injectable (109-122 CNY) and second-/third-line (124-327 CNY) antibiotics (Table 3).

Over the study period, procurement volumes and spending on antibiotics increased in county hospitals: an increase of 11.17 thousand DDDs and 450.62 CNY thousand in each hospital in the test group compared with an increase of 13.63 thousand DDDs and 650.90 CNY thousand in each hospital in the control group each month. However, the average procurement price of antibiotics remained largely unchanged in both groups: a decrease of $2.95 \mathrm{CNY}$ (3.53\%) in control hospitals compared with 0.98 CNY $(1.02 \%)$ in test hospitals.

The DID results revealed that non-reform was associated with a $14.79 \%$ reduction in the total cost of antibiotics $(p=0.013), \quad$ a $14.79 \%$ reduction in the cost of injectable antibiotics $(p=0.022)$ and a $17.30 \%$ reduction in the cost of first-line antibiotics $(p=0.030)$. Non-reform was also associated with a $17.30 \%$ reduction in the total volume of second-line antibiotics $(p=0.013)$. No significant associations between the reform and the price of the procured antibiotics were found (Table 4).

\subsection{Robustness Test}

Quasi-natural experiment studies may incur concern about selection bias. We performed time series analyses and compared the secular trends of the two groups of hospitals after November 2015 when all the hospitals had implemented the reform (Fig. 1). There was no indication of any 
Table 1 Baseline characteristics of counties in which the participating hospitals are located

\begin{tabular}{lcccc}
\hline County characteristics (as at 2014) & Control group $(n=38)$ & Test group $(n=26)$ & $t$ & $p$ value \\
\hline Population (10,000) & $60.93 \pm 27.75$ & $52.25 \pm 23.27$ & 1.303 & 0.197 \\
GDP per capita (CNY) & $39,705.08 \pm 23,687.79$ & $26,503.19 \pm 11,602.95$ & 2.625 & 0.011 \\
Fiscal revenue as a percentage of GDP (\%) & $8.32 \pm 2.65$ & $8.12 \pm 2.94$ & 0.292 & 0.771 \\
Share of new technology outputs as a percentage of GDP (\%) & $9.22 \pm 6.33$ & $5.86 \pm 3.89$ & 2.399 & 0.020 \\
Per capita disposable income of urban residents (CNY) & $21,855.92 \pm 2264.12$ & $20,317.23 \pm 1574.67$ & 2.99 & 0.004 \\
Urban-rural ratio of per capita disposable income & $2.05 \pm 0.42$ & $2.26 \pm 0.43$ & -1.89 & 0.063 \\
\hline
\end{tabular}

Mean \pm standard division were calculated and presented for each indictor

The $t$ value was derived from independent sample $T$ test

$C N Y$ Chinese yuan, GDP gross domestic product

Table 2 Results of modified Park tests and Box-Cox tests to identify family distribution and link function of outcome indicators in the generalised linear regression models

\begin{tabular}{|c|c|c|c|c|}
\hline \multirow{2}{*}{$\begin{array}{l}\text { Outcome variables } \\
\text { Cost }\end{array}$} & \multicolumn{2}{|c|}{ Modified Park test for family distribution } & \multicolumn{2}{|c|}{ Box-Cox test for link function } \\
\hline & & & & \\
\hline All antibiotics & 2.37 & Gamma & 0.13 & $\log$ \\
\hline Oral antibiotics & 2.00 & Gamma & 0.17 & $\log$ \\
\hline Injectable antibiotics & 2.41 & Gamma & 0.16 & $\log$ \\
\hline First-line antibiotics & 2.09 & Gamma & 0.10 & $\log$ \\
\hline Second-line antibiotics & 2.77 & Gamma & 0.10 & $\log$ \\
\hline Third-line antibiotics & 2.46 & Gamma & 0.047 & $\log$ \\
\hline \multicolumn{5}{|l|}{ DDD } \\
\hline All antibiotics & 2.71 & Gamma & 0.068 & $\log$ \\
\hline Oral antibiotics & 2.61 & Gamma & 0.087 & $\log$ \\
\hline Injectable antibiotics & 2.74 & Gamma & 0.064 & $\log$ \\
\hline First-line antibiotics & 2.83 & Gamma & 0.083 & $\log$ \\
\hline Second-line antibiotics & 2.56 & Gamma & 0.010 & $\log$ \\
\hline Third-line antibiotics & 2.44 & Gamma & -0.082 & $\log$ \\
\hline \multicolumn{5}{|l|}{ Unit price per DDD } \\
\hline All antibiotics & 1.36 & Poisson & 0.13 & $\log$ \\
\hline Oral antibiotics & 2.10 & Gamma & 0.068 & $\log$ \\
\hline Injectable antibiotics & 1.38 & Poisson & 0.22 & $\log$ \\
\hline First-line antibiotics & 1.01 & Poisson & 0.11 & $\log$ \\
\hline Second-line antibiotics & 1.92 & Poisson & 0.28 & $\log$ \\
\hline Third-line antibiotics & 0.18 & Gaussian & 0.73 & Identity \\
\hline
\end{tabular}

Coefficients derived from the modified Park tests were used to determine family distribution in the generalised linear regression models: 0 indicates Gaussian distribution with the variance unrelated to the mean; 1 indicates Poisson distribution with the variance equal to the mean; 2 indicates Gamma distribution with the variance exceeding the mean. Coefficients derived from the Box-Cox tests were used to determine link function: 0 for $\log$ link; 0.5 for square root link; 1 for identity link

$D D D$ defined daily dose differences between the two groups in secular trends ( $p=0.514, p=0.889$, and $p=0.706$, respectively, for trends in volume, cost and unit price per DDD).

To test the robustness of our findings, we performed DID analyses on the truncated sample of data from November 2015 to December 2016. We assumed that the reform occurred in June 2016 instead of the actual November 2015. The rationale of the test is that if the differences between the test and control groups prior to November 2015 were driven by selection bias due to some unobserved, time-varying heterogeneities, then these heterogeneities would lead to a placebo result in the truncated sample, similar to the early findings [43, 44]. The results showed that estimates of the placebo tests were either insignificant or had conflicting signs (Table 5). This suggests that our primary findings were unlikely to be caused by selection bias. 
Table 3 Volume (defined daily dose), cost and unit price of procured antibiotics in county hospitals

\begin{tabular}{|c|c|c|c|c|c|}
\hline \multirow[t]{2}{*}{ Outcome indicators } & \multirow[t]{2}{*}{ Overall } & \multicolumn{2}{|c|}{ November 2014-November 2015} & \multicolumn{2}{|c|}{ December 2015-December 2016} \\
\hline & & Test group (pre-reform) & Control group & Test group (post-reform) & Control group \\
\hline \multicolumn{6}{|c|}{ Average cost (CNY in thousands) of procured antibiotics per hospital per month (\% as a share in total) } \\
\hline Total & 907.38 & 519.29 & 674.12 & 969.91 & 1325.02 \\
\hline Injectable & $826.14(91.05)$ & $465.83(89.71)$ & $599.01(88.86)$ & $889.67(91.73)$ & $1219.90(92.07)$ \\
\hline Oral & $81.24(8.95)$ & $53.46(10.29)$ & $75.11(11.14)$ & $80.24(8.27)$ & $105.13(7.93)$ \\
\hline First-line & $319.91(35.26)$ & $202.02(38.90)$ & $257.35(38.18)$ & $343.05(35.37)$ & 436.28 (32.93) \\
\hline Second-line & $542.45(59.78)$ & $287.69(55.40)$ & $392.94(58.29)$ & $565.74(58.33)$ & $825.43(62.30)$ \\
\hline Third-line & $45.02(4.96)$ & $29.58(5.70)$ & $23.84(3.54)$ & $61.09(6.30)$ & $63.33(4.78)$ \\
\hline \multicolumn{6}{|c|}{ Average volume (DDDs in thousands) of procured antibiotics per hospital per month ( $\%$ as a share in total) } \\
\hline Total & 23.13 & 15.22 & 17.48 & 26.39 & 31.11 \\
\hline Injectable & $14.00(60.53)$ & $8.49(55.78)$ & $11.18(63.96)$ & $15.68(59.42)$ & $18.93(60.85)$ \\
\hline Oral & $9.13(39.47)$ & $6.73(44.22)$ & $6.29(35.98)$ & $10.71(40.58)$ & $12.19(39.18)$ \\
\hline First-line & $15.53(67.14)$ & $10.87(71.42)$ & $11.45(65.50)$ & $17.90(67.83)$ & $20.59(66.18)$ \\
\hline Second-line & $7.23(31.26)$ & $3.94(25.89)$ & $5.79(33.12)$ & $8.11(30.73)$ & $10.00(32.14)$ \\
\hline Third-line & $0.38(1.64)$ & $0.38(2.50)$ & $0.24(1.37)$ & $0.41(1.55)$ & $0.51(1.64)$ \\
\hline \multicolumn{6}{|c|}{ Average unit price per DDD of procured antibiotics (CNY) } \\
\hline Total & 91.62 & 86.49 & 95.47 & 83.54 & 96.45 \\
\hline Injectable & 116.94 & 113.81 & 118.77 & 108.97 & 121.66 \\
\hline Oral & 17.77 & 14.64 & 20.64 & 16.60 & 18.49 \\
\hline First-line & 33.02 & 29.38 & 37.58 & 29.85 & 34.56 \\
\hline Second-line & 130.90 & 132.40 & 127.28 & 123.81 & 135.50 \\
\hline Third-line & 307.40 & 295.36 & 326.78 & 295.68 & 310.98 \\
\hline
\end{tabular}

$C N Y$ Chinese Yuan, $D D D$ defined daily dose

\section{Discussion}

This study assessed the impact of hospital reforms on the procurement of antibiotics in county public hospitals in Hubei, China. Overall, there was an increasing trend in procurement volumes and spending on antibiotics in all county public hospitals after the reform, even though the procurement price of antibiotics remained largely unchanged. The DID results suggest the reform was associated with an increase in the cost of procured antibiotics, particularly those administered via injection and first-line antibiotics, and an increase in the volume of second-line antibiotics.

Several underlying reasons exist for the increased cost of procured antibiotics. First, county public hospitals in China continue to face serious financial challenges despite increased government investment [45]. The incomes of hospital employees are linked to hospital revenues, which are mainly determined by the volume of services. The government budget for secondary hospitals (mostly county hospitals) as a share of hospital revenues increased only slightly from $9.39 \%$ in 2012 to $12.81 \%$ in 2016 [46]. Although the zero-markup policy means county hospitals can no longer profit from the sale of medicines, they can still charge a fee for medicine-associated services, such as injections.

Second, the reform measures have little, if any, effect on the promotional activities of pharmaceutical suppliers. It is commonly believed that pharmaceutical suppliers may have continued to offer volume-based commissions to prescribers 'under the table'. Many large pharmaceutical companies also sponsor doctors and/or their professional bodies for academic activities. Some doctors use their low government-defined salary to justify these commissions [18].

Third, the loss of profit from the sale of medicines may have inadvertently encouraged more hospital admissions. Arguably, some admissions may be unnecessary, but they can contribute to profitable revenues, such as accommodation services in county hospitals. Hospital admissions also increase the chance of the parenteral administration of medicines, for which a consumables and services fee can be charged [33]. A recent study observed increasing inpatient activities, including increased expenses in intravenous infusion, electrotherapy, acupuncture, and nursing-related 
Table 4 DID Results from generalised linear regression analyses

\begin{tabular}{|c|c|c|c|c|c|c|c|c|c|}
\hline \multirow{2}{*}{$\begin{array}{l}\text { Outcome } \\
\text { indicators }\end{array}$} & \multirow[t]{2}{*}{$N$} & \multirow[t]{2}{*}{ Coefficient } & \multirow[t]{2}{*}{$p$ value } & \multirow{2}{*}{$\begin{array}{l}\text { Benjamini- } \\
\text { Hochberg } \\
\text { significance }\end{array}$} & \multirow[t]{2}{*}{$95 \% \mathrm{CI}$} & \multirow[t]{2}{*}{ Robust SE } & \multicolumn{3}{|c|}{ Goodness-of-fit tests } \\
\hline & & & & & & & AIC & $\mathrm{BIC}$ & Chi-squared \\
\hline \multicolumn{10}{|c|}{ Cost of procured antibiotics } \\
\hline Total & 22,713 & -0.16 & 0.013 & S & -0.29 to -0.034 & 0.064 & 23.79 & $-173,507.8$ & $81,107.20 * * *$ \\
\hline Oral & 5800 & -0.062 & 0.460 & NS & -0.23 to 0.10 & 0.085 & 21.50 & $-40,068.02$ & $10,419.89 * * *$ \\
\hline Injectable & 16,913 & -0.16 & 0.022 & $\mathrm{~S}$ & -0.29 to -0.023 & 0.069 & 24.21 & $-126,109.9$ & $50,487.46^{* * *}$ \\
\hline First-line & 11,973 & -0.19 & 0.030 & $\mathrm{~S}$ & -0.37 to -0.019 & 0.090 & 22.90 & $-79,471.19$ & $35,355.20 * * *$ \\
\hline Second-line & 9156 & -0.13 & 0.163 & NS & -0.32 to 0.054 & 0.096 & 24.56 & $-68,396.78$ & $22,757.94 * * *$ \\
\hline Third-line & 1584 & -0.11 & 0.547 & NS & -0.48 to 0.25 & 0.19 & 22.99 & -9357.73 & $2487.68 * * *$ \\
\hline \multicolumn{10}{|c|}{ Volume (DDDs) of procured antibiotics } \\
\hline Total & 22,713 & -0.048 & 0.444 & NS & -0.17 to 0.074 & 0.062 & 16.54 & $-182,440.8$ & $83,574.35 * * *$ \\
\hline Oral & 5800 & 0.063 & 0.402 & NS & -0.084 to 0.21 & 0.075 & 17.40 & $-40,418.51$ & $11,507.98 * * *$ \\
\hline Injectable & 16,913 & -0.14 & 0.069 & NS & -0.30 to 0.011 & 0.079 & 16.07 & $-131,604.8$ & $63,016.08 * * *$ \\
\hline First-line & 11,973 & 0.028 & 0.736 & NS & -0.13 to 0.19 & 0.082 & 17.01 & $-88,620.58$ & $37,112.34 * * *$ \\
\hline Second-line & 9156 & -0.19 & 0.032 & $\mathrm{~S}$ & -0.37 to -0.017 & 0.091 & 15.97 & $-70,147.39$ & $22,776.77 * * *$ \\
\hline Third-line & 1584 & -0.0051 & 0.98 & NS & -0.41 to 0.40 & 0.21 & 12.59 & -8605.61 & $3595.26 * * *$ \\
\hline \multicolumn{10}{|c|}{ Average price per DDD of procured antibiotics (CNY) } \\
\hline Total & 22,713 & 0.036 & 0.486 & NS & -0.066 to 0.14 & 0.052 & 53.22 & $885,415.7$ & $2,509,287.49 * * *$ \\
\hline Oral & 5800 & -0.10 & 0.239 & NS & -0.28 to 0.070 & 0.089 & 27.05 & $79,277.97$ & $143,170.44 * * *$ \\
\hline Injectable & 16,913 & 0.050 & 0.342 & NS & -0.053 to 0.15 & 0.052 & 59.33 & $770,543.7$ & $2,287,719.04 * * *$ \\
\hline First-line & 11,973 & -0.10 & 0.088 & NS & -0.22 to 0.015 & 0.059 & 26.47 & $156,510.2$ & $398,925.10^{* * *}$ \\
\hline Second-line & 9156 & 0.075 & 0.239 & NS & -0.05 to 0.20 & 0.064 & 63.66 & $463,126.9$ & $1,055,398.45^{* * *}$ \\
\hline Third-line & 1584 & -8.70 & 0.695 & NS & - 52.20 to 34.80 & 22.19 & 58.48 & $72,766.75$ & $105,739.38$ *** \\
\hline
\end{tabular}

Bold values indicate significance of $p$ value $(p<0.05)$

$A I C$ Akaike information criterion, $B I C$ Bayesian information criterion, $C I$ confidence interval, $D D D$ defined daily doses, $D I D$ difference in differences, $N S$ not significant, $S$ significant, $S E$ standard error

$* * * p<0.001$
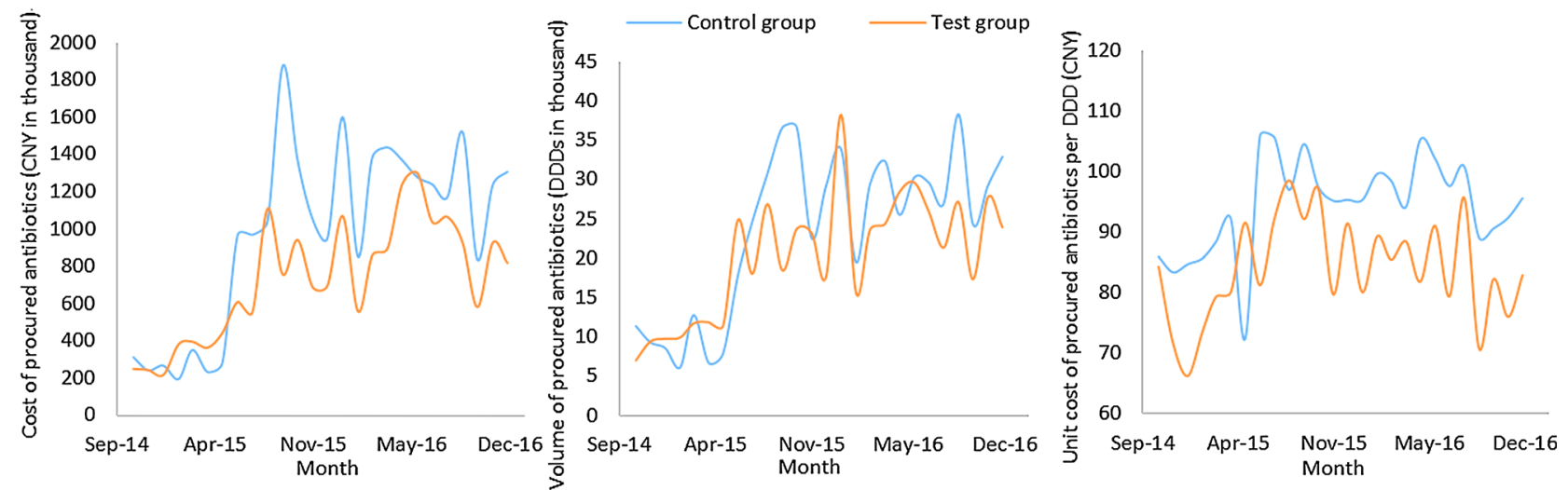

Fig. 1 Average volume, cost and unit price of procured antibiotics per hospital by month. $C N Y$ Chinese Yuan, $D D D$ defined daily dose

services in county public hospitals as a result of the reform [37].

Finally, zero markup on the sale of medicines may have improved the affordability of medicines. Consequently, consumers may request more prescriptions with perceived greater efficacy. There is a common belief in China that intravenous infusion is more effective than oral pills $[23,47]$. It is also not unusual for patients to demand antibiotics without proper indications [48, 49]. A qualitative study revealed that patients with a common cold in 
Table 5 Placebo tests (DID analyses) using the truncated sample of data from November 2015 to December 2016

\begin{tabular}{|c|c|c|c|c|c|c|c|c|}
\hline $\begin{array}{l}\text { Outcome } \\
\text { indicators }\end{array}$ & $N$ & $\begin{array}{l}\text { Modified Park } \\
\text { test }\end{array}$ & $\begin{array}{l}\text { Box-Cox } \\
\text { test }\end{array}$ & Coefficient & $p$ value & $\begin{array}{l}\text { Benjamini-Hochberg } \\
\text { significance }\end{array}$ & $95 \% \mathrm{CI}$ & $\begin{array}{l}\text { Robust } \\
\text { SE }\end{array}$ \\
\hline \multicolumn{9}{|c|}{ Cost of procured antibiotics } \\
\hline Total & 16,488 & 2.37 & 0.13 & 0.034 & 0.54 & NS & $\begin{array}{c}-0.075 \text { to } \\
0.14\end{array}$ & 0.056 \\
\hline Oral & 4222 & 2.00 & 0.17 & 0.18 & 0.008 & S & 0.050 to 0.31 & 0.068 \\
\hline Injectable & 12,266 & 2.41 & 0.16 & 0.0084 & 0.886 & NS & -0.11 to 0.12 & 0.059 \\
\hline First-line & 8681 & 2.09 & 0.10 & 0.14 & 0.034 & S & 0.01 to 0.27 & 0.067 \\
\hline Second-line & 6655 & 2.77 & 0.10 & -0.054 & 0.451 & NS & $\begin{array}{c}-0.19 \text { to } \\
0.086\end{array}$ & 0.072 \\
\hline Third-line & 1152 & 2.46 & 0.047 & -0.018 & 0.904 & NS & $\begin{array}{l}-0.304 \text { to } \\
0.27\end{array}$ & 0.15 \\
\hline \multicolumn{9}{|c|}{ Volume of procured antibiotics (DDDs) } \\
\hline Total & 16,488 & 2.48 & 0.079 & 0.11 & 0.034 & $S$ & 0.0083 to 0.21 & 0.053 \\
\hline Oral & 4222 & 2.52 & 0.107 & 0.16 & 0.016 & $S$ & 0.030 to 0.29 & 0.067 \\
\hline Injectable & 12,266 & 2.63 & 0.077 & 0.066 & 0.294 & NS & $\begin{array}{l}-0.057 \text { to } \\
0.19\end{array}$ & 0.063 \\
\hline First-line & 8681 & 2.52 & 0.095 & 0.13 & 0.070 & $S$ & $\begin{array}{l}-0.010 \text { to } \\
0.26\end{array}$ & 0.80 \\
\hline Second-line & 6655 & 2.59 & 0.029 & 0.063 & 0.333 & NS & $\begin{array}{c}-0.065 \text { to } \\
0.19\end{array}$ & 0.066 \\
\hline Third-line & 1152 & 2.33 & -0.068 & -0.045 & 0.758 & NS & -0.33 to 0.24 & 0.15 \\
\hline \multicolumn{9}{|c|}{ Unit price per DDD of procured antibiotics } \\
\hline Total & 16,488 & 1.37 & 0.11 & 0.027 & 0.487 & NS & $\begin{array}{c}-0.049 \text { to } \\
0.10\end{array}$ & 0.039 \\
\hline Oral & 4222 & 2.17 & 0.037 & 0.014 & 0.794 & NS & $\begin{array}{l}-0.092 \text { to } \\
0.12\end{array}$ & 0.054 \\
\hline Injectable & 12,266 & 1.39 & 0.22 & 0.018 & 0.653 & NS & $\begin{array}{l}-0.060 \text { to } \\
0.095\end{array}$ & 0.040 \\
\hline First-line & 8681 & 1.06 & 0.075 & 0.061 & 0.192 & NS & $\begin{array}{c}-0.031 \text { to } \\
0.15\end{array}$ & 0.047 \\
\hline Second-line & 6655 & 1.98 & 0.27 & 0.0025 & 0.961 & NS & $\begin{array}{c}-0.099 \text { to } \\
0.10\end{array}$ & 0.052 \\
\hline Third-line & 1152 & 0.21 & 0.76 & -9.46 & 0.444 & NS & $\begin{array}{c}-33.71 \text { to } \\
14.78\end{array}$ & 12.37 \\
\hline
\end{tabular}

$C I$ confidence interval, $D D D$ defined daily dose, $N S$ not significant, $S$ significant, $S E$ standard error

China usually sought self-medication first but turned to injectable treatments if symptoms persisted simply because "pills have failed" [23]. This distorted perception and consumer demand may put additional pressure on prescribers [9], exacerbating overprovision and the irrational use of injections.

Our findings have some policy implications. Hospitals operate within a very complex system. Many of the problems are shaped by multiple policy arrangements involving various stakeholders. A systems approach to health reform is critical. Piecemeal remedies rarely fix a problem without leading to unintended consequences if health organisations can easily find a way to take advantage of the reform for their own financial gains. It is essential that strategies that can align policy goals with the financial incentives of health providers are developed, at both individual and organisational levels [45]. These often require changes in governance structure, accountability, payment mechanisms and autonomy of decision making [50-52].

To our knowledge, this is the first study of its kind to examine the impact of hospital reform on the procurement of antibiotics. Our findings complement existing evidence from the literature, which points to the potential risk of cost shifting from outpatient to inpatient care [37] and from supplier-induced sale of medicines to supplier-induced demand for services due to the reform [36]. This study has several strengths over previous studies. We used a large sample and also used institutionalised data, which avoids much of the bias of sampling. We also examined the robustness of the findings. 
This study has several limitations. First, data were drawn from procurement records, which do not directly reflect the actual use of medicines. We were unable to evaluate the appropriateness of antibiotic use at the individual patient level. Second, medicines used for outpatient and inpatient care were not separated in the procurement records. This prevented us from exploring the effects of the reform on outpatient and inpatient care separately.

\section{Conclusion}

The public hospital reform in China diminished the profit margin on sales of medicines in public hospitals, but the entire funding structure for hospitals remained largely unchanged, which negated the potential of the reform to contain the excessive procurement of antibiotics. On the contrary, county public hospitals procure more antibiotics and a greater number of expensive antibiotics, such as those administered via injection, to compensate for the loss of income from the sale of medicines, leading to increased total costs of antibiotics. A systems approach to health reform is critical and will require coordinated changes in funding, governance, management and payment mechanisms.

Acknowledgements This study was supported by the National Natural Science Foundation of China, Grant number 71704058. The authors are also grateful to the staff in Hubei Public Resource Trading Center for their kind help in data collection.

Author contributions Conception and design: YT, CL, XZ and KZ. Collection and assembly of data: YT and KZ. Statistical analysis: YT, $\mathrm{CL}$ and JL. Interpretation: YT, CL, XZ, JL and KZ. Manuscript preparation: YT, CL and JL. Manuscript review: YT, CL JL, XZ and XZ.

\section{Compliance with Ethical Standards}

Funding This study was supported by the National Natural Science Foundation of China, Grant number 71704058. The funding body played no role in the study design; the collection, analysis, and interpretation of data; the writing of the manuscript; or the decision to submit the manuscript for publication.

Conflict of interest Yuqing Tang, Chaojie Liu, Junjie Liu, Xinping Zhang and Keyuan Zuo have no conflicts of interest.

Data availability statement The datasets analysed for the current study are available from the corresponding authors on reasonable request.

Open Access This article is distributed under the terms of the Creative Commons Attribution-NonCommercial 4.0 International License (http://creativecommons.org/licenses/by-nc/4.0/), which permits any noncommercial use, distribution, and reproduction in any medium, provided you give appropriate credit to the original author(s) and the source, provide a link to the Creative Commons license, and indicate if changes were made.

\section{References}

1. Huttner A, Albrich WC, Bochud PY, Gayet-Ageron A, Rossel A, Dach EV, et al. PIRATE project: point-of-care, informatics-based randomised controlled trial for decreasing overuse of antibiotic therapy in Gram-negative bacteraemia. BMJ Open. 2017;7(7):e017996.

2. Laxminarayan R, Duse A, Wattal C, Zaidi AK, Wertheim HF, Sumpradit N, et al. Antibiotic resistance-the need for global solutions. Lancet Infect Dis. 2013;13(12):1057-98.

3. O'Neill J. Antimicrobial resistance: tackling a crisis for the health and wealth of nations. 2014. https://www.west-info.eu/. Cited 12 Sept 2017.

4. Goff DA, Kullar R, Goldstein EJC, Gilchrist M, Nathwani D, Cheng AC, et al. A global call from five countries to collaborate in antibiotic stewardship: united we succeed, divided we might fail. Lancet Infect Dis. 2017;17(2):e56-63.

5. Bogert CAVD, Mestrinaro M, Weerasuriya K. The pursuit of responsible use of medicines: sharing and learning from country experiences. Geneva: World Health Organization; 2012.

6. Heddini A, Cars O, Qiang S, Tomson G. Antibiotic resistance in China-a major future challenge. Lancet. 2009;373(9657):30.

7. Yin X, Song F, Gong Y, Tu X, Wang Y, Cao S, et al. A systematic review of antibiotic utilization in China. J Antimicrob Chemother. 2013;68(11):2445-52.

8. Ren N, Zhou P, Wen X, Li C, Huang X, Guo Y, et al. Point prevalence survey of antimicrobial use in Chinese hospitals in 2012. Am J Infect Control. 2016;44(3):332-9.

9. Mao W, Vu H, Xie Z, Chen W, Tang S. Systematic review on irrational use of medicines in China and Vietnam. PLoS One. 2015;10(3):e0117710.

10. Lin H, Dyar OJ, Rosales-Klintz S, Zhang J, Tomson G, Hao M, et al. Trends and patterns of antibiotic consumption in Shanghai municipality, China: a 6 year surveillance with sales records, 2009-14. J Antimicrob Chemother. 2016;71(6):1723-9.

11. Li J, Song X, Yang T, Chen Y, Gong Y, Yin X, et al. A systematic review of antibiotic prescription associated with upper respiratory tract infections in China. Medicine. 2016;95(19): e3587.

12. Xiao YH, Hou F, Wang J, Yan Q, Sun ZY, Lv XJ. An investigation into socio-economic impact of adverse drug reactions of antibacterial agent irrational use. Chin Health Econ. 2010;29:94-9.

13. Yip WC, Hsiao WC, Chen W, Hu S, Ma J, Maynard A. Early appraisal of China's huge and complex health-care reforms. Lancet (London, England). 2012;379(9818):833-42.

14. Hu S, Tang S, Liu Y, Zhao Y, Escobar ML, de Ferranti D. Reform of how health care is paid for in China: challenges and opportunities. Lancet (London, England). 2008;372(9652): 1846-53.

15. Ran LM, Luo KJ, Wu YC, Yao L, Feng YM. An analysis of China's physician salary payment system. J Huazhong Univ Sci Technol Med Sci. 2013;33(2):309-14.

16. Yip W, Hsiao WC. The Chinese health system at a crossroads. Health Affairs (Project Hope). 2008;27(2):460-8.

17. Tang Y, Liu C, Zhang X. Delivery of essential medicines to primary care institutions and its association with procurement volume and price: a case study in Hubei Province, China. Appl Health Econ Health Policy. 2017;15(1):57-64.

18. Yang W. How does the pharmaceutical industry influence prescription? A qualitative study of provider payment incentives and drug remunerations in hospitals in Shanghai. Health Econ Policy Law. 2016;11(4):379-95.

19. Currie J, Lin W, Zhang W. Patient knowledge and antibiotic abuse: evidence from an audit study in China. J Health Econ. 2011;30(5):933-49. 
20. Currie J, Lin W, Meng J. Addressing antibiotic abuse in China: an experimental audit study. J Dev Econ. 2014;01(110):39-51.

21. Hu J, Mossialos E. Pharmaceutical pricing and reimbursement in China: when the whole is less than the sum of its parts. Health Policy (Amsterdam, Netherlands). 2016;120(5):519-34.

22. Liang H, Ding J, Xue Y. China's drug innovation and policy environment. Drug Discov Today. 2011;16(1-2):1-3.

23. Reynolds L, McKee M. Factors influencing antibiotic prescribing in China: an exploratory analysis. Health Policy (Amsterdam, Netherlands). 2009;90(1):32-6.

24. Zhang W, Liu X, Wang Y, Chen Y, Huang M, Fan M, et al. Antibiotic use in pulmonology wards of Chinese children's hospitals: 2002-2006. J Clin Pharm Ther. 2009;34(1):61-5.

25. Meng Q, Cheng G, Silver L, Sun X, Rehnberg C, Tomson G. The impact of China's retail drug price control policy on hospital expenditures: a case study in two Shandong hospitals. Health Policy Plan. 2005;20(3):185-96.

26. Han S, Liang H, Su W, Xue Y, Shi L. Can price controls reduce pharmaceutical expenses? A case study of antibacterial expenditures in 12 Chinese hospitals from 1996 to 2005. Int J Health Serv. 2013;43(1):91-103.

27. Li Y, Xu J, Wang F, Wang B, Liu L, Hou W, et al. Overprescribing in China, driven by financial incentives, results in very high use of antibiotics, injections, and corticosteroids. Health Affairs (Project Hope). 2012;31(5):1075-82.

28. Guan X, Liang H, Xue Y, Shi L. An analysis of China's national essential medicines policy. J Public Health Policy. 2011;32(3):305-19.

29. Tang Y, Zhang X, Yang C, Yang L, Wang H, Zhang X. Application of propensity scores to estimate the association between government subsidy and injection use in primary health care institutions in China. BMC Health Serv Res. 2013;21(13):183.

30. Chen M, Wang L, Chen W, Zhang L, Jiang H, Mao W. Does economic incentive matter for rational use of medicine? China's experience from the essential medicines program. PharmacoEconomics. 2014;32(3):245-55.

31. Yang L, Liu C, Ferrier JA, Zhou W, Zhang X. The impact of the National Essential Medicines Policy on prescribing behaviours in primary care facilities in Hubei province of China. Health Policy Plan. 2013;28(7):750-60.

32. Yi H, Miller G, Zhang L, Li S, Rozelle S. Intended and unintended consequences of China's zero markup drug policy. Health Affairs (Project Hope). 2015;34(8):1391-8.

33. Zhang S, Zhang W, Zhou H, Xu H, Qu Z, Guo M, et al. How China's new health reform influences village doctors' income structure: evidence from a qualitative study in six counties in China. Hum Resour Health. 2015;05(13):26.

34. CfHSa Information. An analysis report of National Health Services Survey in China. Beijing: Center for Health Statistics and Information; 2009.

35. National Health and Family Planning Commission of China. Statistical bulletin of China's health service development of 2010. http://www.moh.gov.cn. Cited 1 Aug 2017.

36. Zhang $\mathrm{H}, \mathrm{Hu} \mathrm{H}, \mathrm{Wu} \mathrm{C}, \mathrm{Yu} \mathrm{H}$, Dong $\mathrm{H}$. Impact of China's public hospital reform on healthcare expenditures and utilization: a case study in ZJ Province. PLoS One. 2015;10(11):e0143130.
37. Zhang Y, Ma Q, Chen Y, Gao H. Effects of public hospital reform on inpatient expenditures in rural China. Health Econ. 2017;26(4):421-30.

38. Bureau of Statistics of Hubei Province. Hubei statistic year book 2015; 2015. http://www.stats-hb.gov.cn/info/iIndex.jsp?cat_id= 10055. Cited 31 Dec 2015.

39. National Health and Family Planning Commission of China. China Health Statistics Yearbook; 2015. http://www.nhfpc.gov. cn/zwgkzt/pwstj/list.shtml. Cited 1 May 2017.

40. Government of Hubei Province. Guidelines for price adjustment of medical services in county-level public hospitals comprehensive reform pilot hospitals in Hubei province. 2014. http://www. macheng.gov.cn/info/1440/14215.htm. Cited 15 Sept 2017.

41. Andersson K, Petzold MG, Sonesson C, Lonnroth K, Carlsten A. Do policy changes in the pharmaceutical reimbursement schedule affect drug expenditures? Interrupted time series analysis of cost, volume and cost per volume trends in Sweden 1986-2002. Health Policy (Amsterdam, Netherlands). 2006;79(2-3):231-43.

42. Benjamini Y, Hochberg Y. Controlling the false discovery ratea practical and powerful approach to multiple testing. J R Stat Soc. 1995;57(1):289-300.

43. Angrist JD, Krueger AB. Empirical strategies in labor economics. Soc Sci Electron Publ. 2006;3(1):1277-366.

44. Duflo E, Mullainathan S, Bertrand M. How much should we trust difference-in-difference estimates. Q J Econ. 2004;119(1):249-75.

45. Zhao D, Zhang Z. Qualitative analysis of direction of public hospital reforms in China. Front Med. 2017. https://doi.org/10. 1007/s11684-017-0534-7.

46. Health Mo. China's health statistics yearbook 2012. Beijing: China Statistics Press; 2013.

47. Reynolds L, McKee M. Serve the people or close the sale? Profitdriven overuse of injections and infusions in China's marketbased healthcare system. Int $J$ Health Plan Manag. 2011;26(4):449-70.

48. Ding L, Sun Q, Sun W, Du Y, Li Y, Bian X, et al. Antibiotic use in rural China: a cross-sectional survey of knowledge, attitudes and self-reported practices among caregivers in Shandong province. BMC Infect Dis. 2015;21(15):576.

49. Sun Q, Dyar OJ, Zhao L, Tomson G, Nilsson LE, Grape M, et al. Overuse of antibiotics for the common cold-attitudes and behaviors among doctors in rural areas of Shandong Province, China. BMC Pharmacol Toxicol. 2015;31(16):6.

50. Fu H, Li L, Li M, Yang C, Hsiao W. An evaluation of systemic reforms of public hospitals: the Sanming model in China. Health Policy Plan. 2017;32(8):1135-45.

51. Li L, Fu H. China's health care system reform: progress and prospects. Int J Health Plan Manag. 2017;32(3):240-53.

52. Si L, Chen M, Palmer AJ. Has equity in government subsidy on healthcare improved in China? Evidence from the China's National Health Services Survey. Int $J$ Equity Health. 2017;16(1):6. 